www.jmscr.igmpublication.org

crossref DOI: http://dx.doi.org/10.18535/jmscr/v3i8.62

Journal Of Medical Science And Clinical Research

\title{
Migraine: Study of Clinical Profile in Clinical Practice
}

\author{
Authors

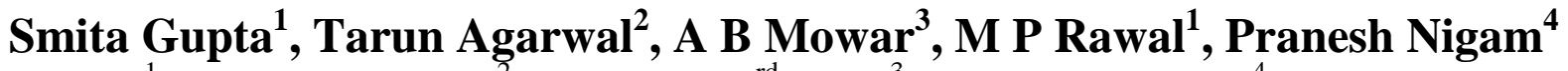 \\ ${ }^{1}$ Assistant Professor, ${ }^{2}$ Postgraduate $3{ }^{\text {rd }}$ Year, ${ }^{3}$ Associate Professor, ${ }^{4}$ Professor \\ ${ }^{1,2,3,4}$ Department Of Medicine, Shri Ram Murti Smarak Institute of Medical Sciences, Bhojipura 243202, \\ Bareilly, Uttar Pradesh FAX No: 0581-2582010 \\ Corresponding Author \\ Dr Smita Gupta
}

Assistant Professor, C-4, (OPD-3), SRMS IMS, Bhojipura, Bareilly, UP

Email: smgu2001@yahoo.com, Phone No: 9458702667

\begin{abstract}
Introduction: Headache is one of the common symptoms in clinical practice with a life time prevalence of $30 \%$ in the general population. Migraine is the second most common causes of headache amongst the primary headache syndrome. The clinical presentation of migraine varies from patient to patient and even the same patient from time to time and causing sufficient morbidity. Keeping in view of its variable clinical practice and management the present study was undertaken for the clinical picture, diagnosis and treatment.
\end{abstract}

Material And Methods: All the patients, who came mainly for headache in OPD clinic were analysed for their types and subtypes according to aetiology. The primary headache syndrome patients were again analysed and only patients with migraine were included in this study. They were diagnosed by other criteria laid down by the headache classification subcommittee of the International Headache Society ${ }^{1,2}$. All of them were interrogated for headache, its time of onset, duration, character, site and associated features. They were subjected to detailed physical examination and relevant investigations.

Observations And Results: During the period of April 2014 to March 2015, 2300 patients attended the OPD clinic and of whom there were 924 cases (40.1\%) complained mainly for headache. Out of 924 cases there were 224 cases $(24.2 \%)$ belonged to primary headache syndrome of total OPD attendance. Amongst these primary headache syndrome, there were 38 (16.9\% or $0.8 \%$ of total OPD attendance) were of migraine who constituted the clinical material for the study. 10 of them (26.3\%) presented as classical migraine ie., migraine with aura. The 4 phases of migraine ie., prodrome, aura, headache and post drome blended imperceptibly with one another during the course of attack. It is common in $4^{\text {th }}$ decade of life (34.8 +/-11.8yrs). Typical pattern of headache ie., recurrent paroxysmal headache associated with nausea, vomiting, photophobia and phonophobia was seen in $89.4 \%$ of cases. Neurological manifestation was seen by $31.3 \%$ of cases in the formed paresthesia, vertigo, altered consciousness and syncope. Clinical examination and investigation could not reveal any positive finding. They all responded to non pharmacological and pharmacological methods. Propanolol and amitryptiline had good response.

Conclusion: Migraine is a common condition amongst the primary headache syndrome. If diagnosed early and treated with change in life style and use of prophylaxis with Propanolol and Amitryptiline will prevent the morbidity.

Keywords: Migraine, Primary Headache, Aura 


\section{INTRODUCTION}

Headache is one of the most common symptoms in clinical practice with a life time prevalence of $30 \%$ in general population. Migraine is the second most common cause of the headache among the Primary Headache Syndrome. Diagnosis and management is based on a careful clinical approach that is augmented by an understanding of the anatomy, physiology and pharmacology of the nervous system pathways that mediate the various headache syndromes.

The international headache society has classified headache as primary and secondary. ${ }^{1,2}$ Primary headaches are those in which headache and its associated factors are the disorder itself, whereas secondary are those caused by exogenous disorders. Primary headaches often result in considerable morbidity and affects the patients quality of life. Life threatening headache is relatively uncommon. The most common primary headaches are migraine, tension type headache and cluster headache. Migraine is second most common causes of headache, afflicts approximately $15 \%$ of women and $6 \%$ of men. ${ }^{1}$

A useful description of migraine is a benign and recurring syndrome of headache associated with other symptoms of neurological dysfunction admixtures. Migraine can often be recognized by its activators referred to as triggers. ${ }^{1}$

Because of its variability, the present study was undertaken to analyze the migraine in clinical practice and various factors responsible for it and manage accordingly.

\section{MATERIAL AND METHODS}

All cases with headaches were analyzed and those who had repeated attacks lasting 4-72 hours with a normal physical examination, and no other reasonable cause for headache and having ${ }^{1,4}$

\section{At least two of the following features-}

- Unilateral pain and rarely bilateral, intermittent or continuous.

- Throbbing in character

- Aggravated by movement, posture, coughing and straining
- Moderate or severe in intensity

2. Plus at least one of the following features-

- Nausea and/or vomiting

- Photophobia and/or Phonophobia.

3. Tempo of onset, time of onset and location of maximal pain.

All of them were asked detailed history pertaining to headache and subjected to detailed examination with reference to detect any neurological deficit.Routine examination of blood, urine and stool with $\mathrm{x}$-ray chest postero-antero view were performed with relevant biochemical tests, C.T scan for brain and CSF examination wherever is needed.

\section{DIAGNOSTIC CRITERIA}

1. COMMON MIGRAINE- that is migraine without aura.

At least 5 attacks and each attack lasting for 4-72 hours (untreated or unsuccessful treatment), unilateral and become bilateral, pulsating moderate to severe in intensity, aggravated by walking, climbing stairs, menstruation etc.

Headache often associated with nausea and or vomiting, photophobia and/or phonophobia.

2. CLASSICAL MIGRAINE- that is migraine with aura.

Prodromal symptom usually visual, depression, unilateral patchy scotomata, hemianopia, cortical, flashes of light, jagged lines.

Sometimes transient, aphasia, tingling, numbness, vague weakness on one side, nausea and/or vomiting.

Prodrome present for few minutes to an hour.

Prodrome followed by headache, which started with unilateral and later become bilateral.

Prefers to lie in quiet and dark atmosphere.

Temporal and superficial arteries pulsating.

\section{OBSERVATION NAD RESULTS}

One of us in OPD clinic examined and advised 2300 cases during April 2014 to March 2015, who experienced headache once in their life. Amongst these, 224 subjects (24.2\%) were of primary 
headache (Table 1) and 381 of total 224 (16.9\%) were suffering from migraine. 10 of them $(28.36 \%)$ were having aura and rest of them were without aura $(73.7 \%)$ termed as classical migraine.

\section{Table 1: Clinical Types Of Headache}

1. Total number of OPD cases during march 2014 to February 2015 - 2300 cases

2. Number of patients having headache -924 cases or $40.1 \%$

3. Incidence of migraine amongst headache cases - 38 out of 924 cases $(4.11 \%)$

4. Primary headache -224 of total 924 cases (24.2\%)

Subtypes :

a. Migraine -38 cases $(16.9 \%)$

- Without aura -28 cases $(73.7 \%)$

- With aura - 10 cases $(26.3 \%)$

b. Tension headache -166 cases $(74.1 \%)$

c. Exertional headache -18 cases $(8.1 \%)$

d. Cluster headache -2 cases $(0.9 \%)$

10 cases who had aura in the form of shimmering and zigzag lines across the visual field lasting for 10-15 minutes and some of them (6 cases or $1.5 \%$ ) had a feeling of tingling and numbness lasting for another 10-15 minutes. The 4 phases of migraine blend imperceptibly with one another develop the course of the attack. Each and every patient had episodic paroxysmal headache and $89.4 \%$ of patient presented with the triad of migraine i.e, paroxysmal headache, nausea and /or vomiting and some of them with aura in the form of visual and parasthesias, tingling and numbness (table 2).It was mainly seen in $4^{\text {th }}$ decade of life (34.8+/- 11.8 years) and predominantly in females (male:female $=1: 1.7$ ). Photophobia and phonophobia were seen in $52.6 \%$ and $42.1 \%$ of cases respectively and these patients like to be in dark and calm and quiet room. Most of them were educated $(78.9 \%)$ and belongs to middle class and above $(63.1 \%)$.

Duration of the attack (migraine) varies from 1-6 years with mean +/-SD, 2.6+/- 1.8 years. Each attack lasted for an hour or so but in 20 cases or
$52.6 \%$ had attacks lasting for 1-2 days. Frequency of attacks was 1-2 per month initially which increased from the last 2-3 years to 6-8 per month which troubled them. In 8 cases or $21.3 \%$ the pain persisted for all the 24 hours with at times increasing in intensity. Pain was started on one side of head and later in $31.3 \%$ of cases it became bilateral in the region of frontal and temporal area. 6 females $(13.8 \%)$ had migraine attack during the menstruation i.e. appear just before the start of menses and persisted throughout the menstrual period (4-6 days). They got relieved with treatment. Family history of migraine was present in 6 cases or $13.8 \%$. Clinical examination and various investigations could not reveal any significant finding.

All of them were treated initially with analgesics. Dihydroergotamine was not tolerated by 8 cases (21.1\%). They were switched to amitryptiline 25 $\mathrm{mg}$ at bed time and propanolol $40 \mathrm{mg}$ (extended release) and dose increased as per the response to treatment.

Non pharmacological treatment was also given to them. They were (30 cases or $78.9 \%$ ) advised to have relaxing yogic exercises, pranayam, steam inhalation which provided them some relief but not lasting so switched to usual treatment. All of them were advised to have regulated life style with healthy diet, regular exercise and sleep. Ashwagandha was also tried in 16 cases (42.1\%) for sound sleep and relaxation. They were asked to avoid caffeine and alcohol etc.

Table 2: Clinical Profile of Migraine Cases $(n=38)$ Age variants - 22- 56 yrs

Age - mean ISD - 34.8 +/- 11.8 yrs

Males -14 cases $-36.2 \%$

Females -24 cases $-63.2 \%$

Male : female ratio $=1: 1.7$

$\begin{array}{lcc}\text { Symptomatology: } & \text { No } & \text { \% } \\ \text { Nausea } & 34 & 89.4 \% \\ \text { Vomiting } & 18 & 47.4 \% \\ \text { Diarrhoea } & 8 & 21.1 \% \\ \text { Light headedness } & 30 & 78.9 \% \\ \text { Scalp tenderness } & 16 & 42.1 \% \\ \text { Visual disturbances } & 14 & 36.8 \% \\ \text { Photophobia } & 20 & 52.6 \%\end{array}$




$\begin{array}{lcr}\text { Phonophobia } & 16 & 42.1 \% \\ \text { Paresthesia } & 12 & 31.3 \% \\ \text { Vertigo } & 6 & 15.8 \% \\ \text { Altered consciousness } & 8 & 21.1 \% \\ \text { Syncope } & 4 & 10.5 \% \\ \text { Confusional state } & 4 & 10.5 \% \\ \text { Educated above high school - } & 15 & (78.9 \%) \\ \text { Middle class and above - } & 12 & (63.1 \%)\end{array}$

\section{Discussion}

924 cases were of mainly headache amongst the 2300 cases seen in OPD clinic giving the incidence of $40.1 \%$ and amongst them these 224 cases $(24.2 \%)$ were of primary headache. There were only 38 cases (16.9\%) of migraine amongst the primary headache. The overall incidence of migraine came to be $0.8 \%$ i.e., of total of 2300 cases. It is described that headache is a frequently encountered neurological symptom ${ }^{3-6}$. Goadsby and Ruskin ${ }^{1}$ described migraine as the second most common cause and affects mainly females (15\%) as we found too that females outnumbered (24 cases, $63.2 \%$ )- with male to female ratio of 1:1.7. it can occur at any age but commonly in fourth decade of life (mean +/-SD $=34.8+/-4.8 \mathrm{yrs}$ ) the same was also observed by Kumar and Clarks who described that this pain began at 40 years of age $^{6,7}$.

Migraine was mainly seen in educated persons (78.98\%) i.e., above highschool and middle class and above group $(63.19 \%)$, as they are more under the stress and strain of life $\mathrm{e}^{5}$. A closer look at the diagnostic criteria suggests that all headaches features need not be present and fulfilment of any 2 out of 4 will be sufficient for diagnosis ${ }^{6,7}$. We too agree with it. Classical migraine was seen in 10 cases $(26.3 \%)$ but all the 4 phases blend imperceptibly. It is considered to be syndrome. Condition begin as a prodrome consisting of premonitory symptoms followed by aura which might be visual, sensory followed by typical paroxysm of headache which in some of them start from unilateral then become bilateral involving frontal temporal and parietal area. It might be menstrual migraine as seen in 6 females. A useful description of migraine is a benign and recurrent syndrome of headache associated with other symptoms of neurologic dysfunction in varying adversities. The syndromic features clearly suggest that the disease is of brain origin and not merely due to vessel involvement (so called vascular headaches) as was previously believed. Modern functional neuro-imaging has clearly shown involvement of hypothalamus and brain stem during premonitory and headache phase $^{1,3,7}$. Visual disturbances as flashing light and zigzag lines moving across the visual field was related in. We too have observed $36.8 \%$ of such cases. Photophobia and phonophobia is described in literature. We too observed that in $52.6 \%$ and $42.6 \%$ of cases respectively and these patient like to remain in calm and quiet and dark room.

After establishing the diagnosis the next step to assess the extent of the disease and disability by MIDAS score ${ }^{1}$. The patient education is important aspect of migraine management. All of them educated to have regulated life style with healthydiet, regular exercise and sleep. This was advised in present series by certain yogic exercises and relaxation exercises as described in Indian literature as well ${ }^{1,4,8}$. As mentioned in literature patients responded well to analgesics. Triptans were not given as not available. They responded to antidepressants, Amitryptiline and proponalol (extended release) used as preventive measure. The present study also highlighted incidence of tension headache as high as $74.1 \%$ making it as the most common cause of primary headache as also mentioned in the literature.

In conclusion, migraine as the second most common causes of primary headaches if treated well in time by lifestyle modification and regular prophylactic treatment can significantly reduce the morbidity associated with the disease.

\section{References}

1. Goadsby PJ and Raskin NH; Headache in Harrison's Principles of General Medicine $18^{\text {th }}$ edition, Longo DL, Kasper DL, Jameson JL et al. McGraw Hill Medical 
New York, New Delhi 2012, Vol 1, section-1,ch 14 pp:112-128

2. Headache Classification Subcommittee of the International Headache Society, The International Classification of Headache Disorders. Cephalgia, 2004;24 (suppl-1);1160

3. Allen CNS, Lueck CY, Dennis M ; Headache and facial pain in "Davidson's Principles and Practice of Medicine", $20^{\text {th }}$ edition eds. Born NA college NR, Walker BR, Hunter JAA, Churchill Livingston, Elsevier, Edinburg, London, Toranto, 2006, ch 26, pp 1160-1164.

4. Taylor FR : Diagnosis and Classification of headache primary care. Clinics in office practice, 2004,31:293-259

5. Lipton RB, Stewart WF, Ryan RE. Efficacy and safety of acetaminophen, aspirin and caffeine in alleviating migraine headache pain: three double-blind ,randomised, placebo-controlled trials. Arch Neurol. 1998; 55(2):210-217

6. Ravishankar K ; Headache in API Text book Of Medicine $9^{\text {th }}$ edition. Munjal YP, Sharma SK, Agarwal AK, Gupta P. et al The Association Physicians of India, Mumbai 400011, 2012; Vol 1 section 2: ch 2 pp 12-15

7. Kumar $\mathrm{P}$ and Clark $\mathrm{M}$; Headache , Migraine and Facial pain in "Clinical Medicine" $7^{\text {th }}$ edition .Kumar P Clark M Saunders Elesvier, London, Toranto, 2009; ch 21; page 1136-1139

8. Choudhary D; Enigma of a Migraine patient -Migraine in clinical practice series \& Abbott India Ltd Mumbai 2014 